\title{
Otomatisasi Flame Trap Berbasis Sistem Pneumatik Pada Kendaraan Pengangkut BBM
}

\author{
Ahmad Zayadi*1), Masyhudi ${ }^{2)}$, Setyo $A^{3)}$ \\ Program Studi Teknik Mesin Fakultas Teknik dan Sains Universitas Nasional, Jakarta \\ *Korespondensi : zayadiahmad43@gmail.com
}

\begin{abstract}
Flame trap merupakan sebuah perangkat yang dipasang pada knalpot mobil tangki bahan bakar minyak (BBM) dengan bertujuan untuk mencegah terjadinya percikan api yang ditimbulkan akibat hasil pembakaran pada mesin mobil tangka bahan bakar minyak (BBM). Flame trap merupakan fitur keselamatan dasar tetapi memiliki peran sebagai kunci keselamatan pada kendaraan yang berada di area yang mudah terbakar atau zona berbahaya. Hal tersebut dilakukan untuk menghindari terjadinya ledakan di area pengisian bahan bakar minyak (BBM). Flame trap berbasis sistem pneumatik merupakan sebuah inovasi yang dikembangkan untuk memudahkan para awak mobil tangki, sehingga tidak lagi diperlukan pemasangan secara manual serta mengurangi potensi kecelakaan yang berdampak pada kesehatan awak mobil tangki akibat menghirup gas yang dihasilkan dari proses pembakaran pada mesin mobil tangki melalui knalpot. Topik penelitian ini diambil dari kasus di PT. X. Dilakukan perencanaan dan perhitungan alat flame trap berbasis pneumatik, menentukan tekanan pada sistem dan menghitung tekanan hilang yang terjadi. Dengan hasil tekanan minimum yang dibutuhkan sistem sebesar 3, 2482 bar dan tekanan yang tersedia pada tangki 9,8 bar. Maka perancangan alat flame trap berbasis pneumatik dinyatakan aman karena tekanan yang tersedia cukup untuk memenuhi kebutuhan sistem pneumatik.
\end{abstract}

Kata Kunci: Flame trap, Pneumatik, Mobil tangki BBM

Abstract - Flame trap is a device mounted on the exhaust of fuel tank car aims to prevent the occurrence of sparks caused by burning results in the tank car engine. The flame trap is a basic safety feature but has a key safety role in vehicles in combustible areas or dangerous zones. This is done to avoid the explosion in the fuel replenishment area. Flame trap based pneumatic system is an innovation developed to facilitate the crew of the tank car, so it is no longer necessary manual installation and reduce the potential accidents that impact on the health of tank crews due to inhaling gas generated from the combustion in the tank car engine through the exhaust. This final project topic is taken from the case in PT Pertamina (Persero). Planning and calculation of pneumatic-based flame trap tools, determining the pressure on the system and calculating the lost pressure that occurs. With the minimum required system pressure of 3.2482 bar and pressure available on the 9.8 bar tank. So the design of pneumatic based flame trap tools is declared safe because the pressure available is sufficient to meet the needs of the pneumatic system.

Keywords: Flame trap, Pneumatic, fuel tank car 


\section{Pendahuluan}

Di era pasar global saat ini sektor transportasi memainkan peran yang sangat penting dalam pertumbuhan perekonomian nasional untuk jangka panjang. Selama periode 2000 - 2015 konsumsi bahan bakar mendapat kenaikan yang cukup signifikan, tercatat kurang lebih 1,63 juta barel konsumsi minyak per hari pada akhir tahun 2015.Guna menjaga kestabilan akan kebutuhan penggunaan minyak khususnya di dalam negeri PT. X Terminal Bahan Bakar Minyak (BBM) merupakan terminal distribusi BBM di bawah direktorat Supply and Distribution $(\mathrm{SnD})$ Marketing Operational Region (MOR), memiliki tugas pokok yakni menerima, menimbun dan menyalurkan BBM. Terminal ini memiliki fasilitas tangki timbun dan mendistribusikan rata-rata untuk melayani kebutuhan masyarakat melalui outlet retail (SPBU, SPBN). Saat ini, Terminal BBM telah dimodernisasi dengan sistem kontrol otomasi yang terpadu yakni New Gantry System (NGS). Diwilayah Marketing Operation Region, Ada tiga keunggulan yang diberikan dengan diimplementasikan sistem otomasi yang terpadu di TBBM. Yaitu, penggunaan teknologi modern, pengisian mobil tangki secara multi-produk simultan sehingga pelayanan lebih cepat, lebih baik, dengan tetap mengedepankan aspek ketepatan kualitas, kuantitas BBM, serta HSSE. Pada area NGS, filling shed merupakan salah satu sarana fasilitas penyaluran BBM ke mobil tangki. Tentunya mobil tangki yang masuk ke area tersebut harus memiliki standar Pertamina edisi 1 manajemen kendaraan serta sistem yang terpasang pada mobil tangki sudah terintegrasi dengan sarana fasilitas NGS. Mengacu pada panduan Zone Hazardous Location standard International Electrotechnical Commision (IEC) area filling shed termasuk dalam class I adalah lokasi yang memiliki kandungan gas dan uap yang mudah terbakar. Pada proses pengisian BBM ke Mobil Tangki BBM, uap BBM terkonsentrasi dalam jumlah besar di area filling shed, jika terdapat gesekan pada material yang dapat menimbulkan percikan api, maka dapat terjadi sebuah ledakan. Ledakan dapat terjadi disebabkan oleh 3 elemen yaitu sumber api, udara dan bahan mudah terbakar.Untuk menghindari percikan api maka pada mobil tangki diwajibkan menggunakan flame trap sebagai perangkat keamanan dan keselamatan ketika memasuki area Terminal BBM. Saat ini telah dilakukan sebuah inovasi dengan melakukan modifikasi, yaitu menambahkan sistem pneumatik pada flame trap sehingga dapat memudahkan awak mobil tangki untuk menggunakan flame trap ketika memasuki area filling shed. Pada penelitian ini yang akan dibahas adalah perbadingan antara flame trap manual dengan flame trap berbasis pneumatik dengan menghitung dan menganalisa perpindahan panas yang terjadi pada material yang digunakan dan keefektifan pengoperasian alat tersebut.

\section{Tinjauan Literature Pneumatik}

Pneumatik adalah sebuah sistem penggerak yang menggunakan tekanan udara sebagai tenaga penggeraknya. Cara kerja pneumatik sama saja dengan hidrolik yang membedakannya hanyalah fluida kerjanya. Jika pneumatik menggunakan udara sebagai fluida kerjanya sedangkan hidrolik menggunakan cairan oli sebagai fluida kerjanya. Dalam pneumatik tekanan udara inilah yang berfungsi untuk menggerakkan sebuah silinder kerja. Silinder kerja tersebut yang nantinya mengubah tenaga/tekanan udara tersebut menjadi tenaga mekanik (gerakan maju mundur pada silinder).

A. Kelebihan pada sistem pneumatik:

1. Ramah lingkungan/bersih (jika terjadi kebocoran dalam sistem perpipaan).

2. Udara sebagai fluida kerjanya memiliki jumlah yang tak terbatas.

3. Lebih cepat dan responsif jika dibandingkan dengan hidrolik

4. Harganya yang murah.

B. Kekurangan pada sistem pneumatik:

1. Daya mekanik yang dihasilkan kecil

2. Membutuhkan perawatan yang lebih tinggi, karena udara sebagai penggeraknya biasanya kotor dan mengandung air sehingga gesekan antara piston cylinder dan rumah cylinder besar dan mempercepat kerusakan pada air cylinder.

\section{Metodologi Penelitian}

Dalam perencanaan alat maka dibutuhkan data skematik sistem pneumatik sebagai dasar dalam merancang sebuah alat agar dapat mempersiapkan alat dan bahan 
yang akan digunakan pada saat melakukan perhitungan sehingga diharapkan alat bekerja dengan baik dan benar.

metodologi penyelesaian masalah seperti yang dapat dilihat pada diagram alir di bawah ini :

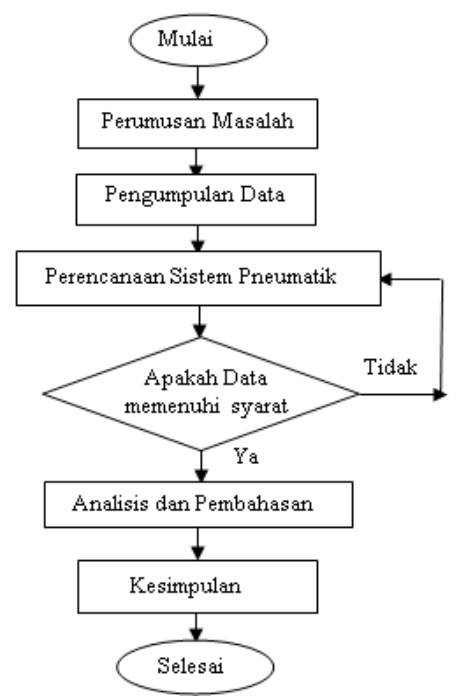

Gambar 3.1. Diagram alir metodologi

\section{Data Masukan}

Proses pengambilan data tersebut dilakukan pada mobil tangki yang digunakan adalah merk Hino seri 500 Type New Ranger FM 260 JD mesin diesel 4 langkah.Sistem Pneumatik.

Dalam perencanaan alat maka dibutuhkan data skematik sistem pneumatik sebagai dasar dalam merancang sebuah alat agar dapat mempersiapkan alat dan bahan yang akan digunakan pada saat melakukan perhitungan sehingga diharapkan alat bekerja dengan baik dan benar.

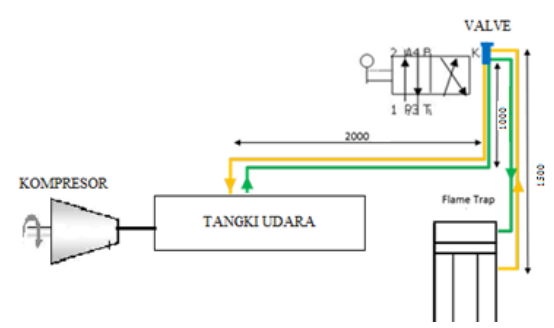

Gambar 3.2 Skematik sistem pneumatik

Dengan melakukan observasi di lapangan, melalui mobil tangki mempunyai 4-5 tangki udara yang tersedia dengan kapasitas masing-masing tangki $9,8 \mathrm{~kg} / \mathrm{cm}^{2}$, sehingga total tekanan udara yang dimiliki sebesar $49 \mathrm{~kg} / \mathrm{cm}^{2}$.

Flame Trap otomatis diciptakan dengan melakukan pemanfaatan tekanan udara yang tersedia di mobil tangki. Komponen exhaust brake padaflame trap otomatis di mobil tangki bekerja dengan menerima tekanan sesuai dengan desain manufakturnya, tentu pada hal ini membutuhkan modifikasi pada jalur pipa udara untuk member tekanan agar kinerjaflame trap dapat bekerja dengan baik. Dengan hasil seperti terlihat pada tabel di bawah ini :

Tabel 3.1.Spesifikasi Mobil Tangki

\begin{tabular}{|c|l|l|}
\hline NO & \multicolumn{1}{|c|}{ PARAMETER } & \multicolumn{1}{c|}{ NILAI } \\
\hline 1 & Tenaga Maksimum & $\begin{array}{l}215 \mathrm{PS} / \\
2500 \mathrm{rpm}\end{array}$ \\
\hline 2 & Torsi Maksimum & $\begin{array}{l}62 \mathrm{kgm} / \\
1500 \mathrm{rpm}\end{array}$ \\
\hline 3 & Jumlah silinder & 6 \\
\hline 4 & $\begin{array}{l}\text { Tekanan Gas Buang } \\
\text { @Maks. load }\end{array}$ & $3 \mathrm{Bar}$ \\
\hline 5 & Tangki Udara & $9,8 \mathrm{kgf} / \mathrm{cm}^{2}$ \\
\hline
\end{tabular}

\section{Menghitung Perencanaan Sistem Pneumatik.}

Perencanaan Sistem Pneumatik untuk Menggerakan Exhaust Brake Valve Menentukan gaya tahan gas buang :

$$
\begin{aligned}
A & =\pi \cdot r^{2} \\
& =3,14 \cdot 2^{2} \\
& =12.56 \mathrm{In}^{2}
\end{aligned}
$$

Menentukan besar gaya minimum yang dibutuhkan :

$$
\begin{aligned}
\mathrm{F} & =\mathrm{p} . \mathrm{A} \\
& =43,5 \cdot 12 \cdot 56 \\
& =546 \cdot 36 \mathrm{~N}=55,71 \mathrm{kgf}
\end{aligned}
$$

4.1 Menentukan Diameter Silinder Pneumatik Untuk mencari diameter silinder pneumatik minimal yang akan dibutuhkan, maka pada perencanaan awal diambil tekanan kerja dari sistem sebesar $3 \mathrm{kgf} / \mathrm{cm} 2$ dan gaya yang dibutuhkan untuk menahan gas buang sebesar $55,71 \mathrm{kgf}$ sedangkan untuk nilai $\mu$ diambil 0,85 (Tenaga fluida pneumatik, 1991 : L78). Data ini kemudian digunakan dalam perencanaan silinder pneumatik. Diameter minimal dapat dicari dengan persamaan. Dengan data yang telah diketahui :

$$
\begin{aligned}
& \mathrm{F}=55,71 \mathrm{kgf} \\
& \mathrm{P}=3 \mathrm{kgf} / \mathrm{cm}^{2} \\
& \mu=0,85 \\
& F=\frac{\pi}{4} \cdot D^{2} \cdot P \cdot \mu \\
& 55,71 \mathrm{kgf}=D^{2} \frac{3,14}{4} \cdot 3 \mathrm{kgf} / \mathrm{cm}^{2} \cdot 0,85 \\
& D^{2}=\frac{55,71 \mathrm{kgf}}{2,00175 \mathrm{kgf} / \mathrm{cm}^{2}}
\end{aligned}
$$


Jurnal Teknologi Kedirgantaraan, Vol, V No. 2, Agustus 2020, P-ISSN 2528-2778, E-ISSN 2684-9704

https://doi.org/ 10.35894/jtk.v5i2.2

$$
\begin{aligned}
& D^{2}=27,83 \mathrm{~cm}^{2} \\
& D=\sqrt{2} 7.83 \mathrm{~cm}^{2} \\
& D=5,28 \mathrm{~cm}=52,8 \mathrm{~mm}
\end{aligned}
$$

4.2 Gaya Dorong Piston

Gaya dorongan Piston dapat diketahui dengan menggunakan persamaan berikut:

$F_{1}=\frac{\pi}{4} D^{2} \cdot P \cdot \mu$

Dengan data yang telah diketahui :

$\mathrm{D}=63 \mathrm{~mm}=6,3 \mathrm{~cm}$

$\mathrm{d}=20 \mathrm{~mm}=2 \mathrm{~cm}$

$\mathrm{P}=3 \mathrm{kgf} / \mathrm{cm}^{2}$

$\mu=0,85$

$$
\begin{aligned}
F_{1} & =\frac{\pi}{4} D^{2} \cdot P \cdot \mu \\
F_{1} & =\frac{3,14}{4}(6,3 \mathrm{~cm})^{2} \cdot 3 \mathrm{kgf} / \mathrm{cm}^{2} \cdot 0,85 \\
& =0,785 \cdot(39,69) \cdot 3 \cdot 0,85 \\
F_{1} & =79,45 \mathrm{kgf}
\end{aligned}
$$

\subsection{Gaya Tarikan Piston}

Gaya tarikan piston dapat diketahui dengan menggunakan persamaan berikut:

$$
\begin{aligned}
F_{2} & =\frac{\pi}{4}\left(D^{2}-d^{2}\right) \cdot P \cdot \mu \\
F_{2} & =\frac{3,14}{4}\left[(6,3 \mathrm{~cm})^{2}-(2,0 \mathrm{~cm})^{2}\right] \cdot 3 \mathrm{kgf} / \mathrm{cm}^{2} \cdot 0,85 \\
& =0,785 \cdot(35,69) \cdot 3 \cdot 0,85 \\
F_{2} & =71,44 \mathrm{kgf}
\end{aligned}
$$

\subsection{Konsumsi Udara}

Kebutuhan konsumsi udara $(\mathrm{V})$ volume pada saat silinder bergerak maju dihitung :

Dari data yang telah diketahui :

$$
\begin{array}{ll}
\mathrm{D}(\text { Diameter silinder }) & =63 \mathrm{~mm} \\
\text { Tekanan kompresor } & =3 \mathrm{bar}=3 \times 10^{5} \mathrm{~Pa} \\
\mathrm{~d}(\text { Diameter rod }) & =20 \mathrm{~mm} \\
\mathrm{~h} \text { stroke } & =10 \mathrm{~cm}=100 \mathrm{~mm}
\end{array}
$$

$$
\begin{aligned}
V & =\frac{\pi}{4} D^{2} \cdot h \\
V & =\frac{3,14}{4}(63 \mathrm{~mm})^{2} \cdot(100 \mathrm{~mm}) \\
V & =0,3116 \mathrm{l} \\
& =311.567 \mathrm{~mm}^{3} \cdot 10^{-6} \frac{\mathrm{l}}{\mathrm{mm}^{\mathrm{a}}}
\end{aligned}
$$

Serta Pada saat silinder bergerak mundur dapat dihitung konsumsi udaranya :

$$
\begin{aligned}
V & =\frac{\pi}{4}\left(D^{2}-d^{2}\right) \cdot h \\
V & =\frac{3,14}{4}\left[(63 \mathrm{~mm})^{2}-(20 \mathrm{~mm})^{2}\right) \cdot(100 \mathrm{~mm}) \\
& =280.166 \mathrm{~mm}^{3} \cdot 10^{-6} \frac{\mathrm{l}}{\mathrm{mm}^{3}} \\
V & =0,2802 l
\end{aligned}
$$

Maka dapat disimpulkan bahwa konsumsi udara yang dibutuhkan silinder dengan $D=63$ $\mathrm{mm}$, panjang langkahnya $100 \mathrm{~mm}$ untuk bergerak maju dan mundur adalah :

Vtotal

$$
\begin{aligned}
& =\text { Vmaju }+ \text { Vmundur } \\
& =0,3116 \mathrm{lt}+0,2802 \mathrm{It} \\
& =0,5918 \mathrm{It}
\end{aligned}
$$

Vtotal

4.5 Besarnya Kecepatan Silinder dan Kapasitas Udara

Besarnya kecepatan silinder didapatkan dari percobaan saat silinder extend dengan menggunakan persamaan :

$$
v=\frac{s}{t}
$$

Dari data yang diketahui :

$\mathrm{s}=100 \mathrm{~mm}=0,1 \mathrm{~m}$

$\mathrm{t}=2 \mathrm{~s}$

$$
v=\frac{0,1}{2}=0,05 \mathrm{~m} / \mathrm{s}
$$

Kapasitas udara dapat dihitung dari persamaan :

$$
\begin{aligned}
\mathrm{Q} & =D^{2} \cdot v \cdot C r \\
& =(0,04 \mathrm{~m})^{2} \cdot 0,05 \cdot 7,9 \\
& =0,000632 \mathrm{~m}^{3} / \mathrm{s}
\end{aligned}
$$

\subsection{Kerugian Tekanan Pada Pipa}

Kerugian tekanan pada pipa dari persamaan Formula Harris tentang kerugian tekanan :

$$
\Delta P=\frac{1,6.10^{3} x Q^{1,85} x L}{d^{5} x P}
$$

Dari data yang telah diketahui :

Tekanan Kerja Sistem $=3$ bar $=3 \times 10^{5} \mathrm{~Pa}$

$\mathrm{Q}\left(\right.$ Konsumsi Udara) $=0,000632 \mathrm{~m}^{3} / \mathrm{s}$

$\mathrm{d}($ Diameter Pipa) $\quad=1 / 4$ " inch $=0,0064 \mathrm{~m}$

$\mathrm{L}$ (Panjang Pipa) $\quad=9 \mathrm{~m}$

$$
\begin{aligned}
& \Delta P=\frac{1,6.10^{3} \times Q^{1,85} \times L}{d^{5} \times P} \\
& \Delta P=\frac{1,6.10^{3} x(0,000632)^{1,85} \times 9}{(0,0064)^{5} \times 3.10^{5}} \\
& \Delta P=\frac{0,0174}{0,0000003}=58.000 \mathrm{~Pa}=0,58 \mathrm{bar} \\
& p l_{1}=0,58 \mathrm{bar}
\end{aligned}
$$

\subsection{Kerugian Tekanan Pada Belokan}

$\mathrm{Di}$ dalam rangkaian sistem pneumatik terdapat belokan - belokan untuk saluran masuk udara ke media - media yang digunakan seperti silinder, katup 2 lubang. Belokan - belokan tersebut terbentuk sudut siku $90^{\circ}$ (standard short radius elbow).

$$
\mathrm{hl}_{b}=\mathrm{C} \cdot \frac{V^{2}}{2 \cdot \mathrm{g}}
$$


Jurnal Teknologi Kedirgantaraan, Vol, V No. 2, Agustus 2020, P-ISSN 2528-2778, E-ISSN 2684-9704

https://doi.org/ 10.35894/jtk.v5i2.2

Dari data yang telah diketahui :

$\mathrm{C}=0,9$

$\mathrm{hl}_{b}=0,9 \cdot \frac{(7,72)^{2}}{2 \cdot 9,81}=2,73$

Jumlah belokan pada rangkaian sistem pneumatik ini terdapat 8 buah, maka kerugian head total pada belokan ialah :

$\mathrm{hl}_{b}=2,73.8=21,84$

$\mathrm{pl}_{2}=21,84 \cdot 1,3 \cdot 9,81$

$=278,52 \mathrm{~N} / \mathrm{m}^{2}=0,0027852$ Bar

\subsection{Perhitungan Kerugian Tekanan}

Udara Total

Maka kerugian tekanan udara total dalam perancangan mekanisme otomatiasi flame trap berbasis sistem pnuematik adalah sebagai berikut :

$$
\begin{aligned}
\mathrm{pl}_{t} & =\mathrm{pl}_{1}+\mathrm{pl}_{2} \\
& =0,58+0,0027852 \\
& =0,587852 \mathrm{bar}
\end{aligned}
$$

\section{v. HASIL PEMBAHASAN}

Dari hasil perhitungan perencanaan dan pengukuran sistem pneumatik flame trap diperoleh parameter. Seperti terlihat pada tabel di bawah ini.

\begin{tabular}{|c|c|c|}
\hline 12. & $\begin{array}{l}\text { Kapasitas } \\
\text { kompressor yang } \\
\text { tersedia }\end{array}$ & 5,9 bar \\
\hline 13. & $\begin{array}{l}\text { Total panjang tube } \\
\text { polyethylene }\end{array}$ & $9 \mathrm{~m}$ \\
\hline 14. & $\begin{array}{l}\text { Diameter } \\
\text { polyethylene }\end{array}$ & $\begin{array}{r}0,0064 \mathrm{~m} \text { atau } \\
1 / 4 "\end{array}$ \\
\hline
\end{tabular}

Tabel 4.1 Hasil Parameter

\begin{tabular}{|c|l|r|}
\hline No. & \multicolumn{1}{|c|}{ Parameter } & Nilai \\
\hline 1. & $\begin{array}{l}\text { Gaya untuk } \\
\text { menggerakan } \\
\text { exhaust brake valve }\end{array}$ & $55,71 \mathrm{kgf}$ \\
\hline 2. & $\begin{array}{l}\text { Perhitungan } \\
\text { diameter silinder } \\
\text { Pneumatik }\end{array}$ & $58,2 \mathrm{~mm}$ \\
\hline 3. & $\begin{array}{l}\text { Gaya Dorongan } \\
\text { pada silinder } \\
\text { pnemuatik }\end{array}$ & $79,45 \mathrm{kgf}$ \\
\hline 4. & $\begin{array}{l}\text { Gaya Tarikan pada } \\
\text { silinder pnemuatik }\end{array}$ & $71,44 \mathrm{kgf}$ \\
\hline 5. & Konsumsi Udara & $0,5918 \mathrm{l}$ \\
\hline 6. & Kecepatan silinder & $0,05 \mathrm{~m} / \mathrm{s}$ \\
\hline 7. & Kapasitas udara & $0,000632 \mathrm{~m} / \mathrm{s}$ \\
\hline 8. & $\begin{array}{l}\text { Kerugian Tekanan } \\
\text { pada pipa }\end{array}$ & $0,58 \mathrm{bar}$ \\
\hline 9. & $\begin{array}{l}\text { Kerugian Tekanan } \\
\text { pada belokan }\end{array}$ & $0,0027852 \mathrm{bar}$ \\
\hline 10. & $\begin{array}{l}\text { Perhitungan } \\
\text { kerugian tekanan } \\
\text { udara total }\end{array}$ \\
\hline 11. & $\begin{array}{l}\text { Tekanan gas buang } \\
\text { pada } \\
\text { maksimal beban }\end{array}$ \\
\hline
\end{tabular}

Tekanan udara minimal dalam perencanaan sistem pneumatik adalah 3,5828 bar. Sedangkan tekanan udara maksimal pada kompresor adalah 5,9 bar. Oleh karena tekanan udara pada peralatan sistem pneumatik lebih besar maka tekanan udara yang dihasilkan kompresor cukup untuk menggerakan flame trap, maka perancangan sistem pneumatik aman dan dapat menggunakan kompresor yang sudah ada pada sistem pneumatik pada mobil dengan mengambil sumber tekanan udara dari tangki penyimpanan mobil dengan kapasitas 9,8 bar. Jumlah minimum kapasitas tekanan yang dibutuhkan untuk menggerakan flame trap adalah $>3,590$ bar. Dan dapat diakomodasi oleh kapasitas tabung kompresor yang tersedia pada kendaraan.

\section{KESIMPULAN}

Dari hasil perencanaan dan perancangan mekanisme otomatisasi flame trap berbasis sistem pneumatik maka dapat disimpulkan berikut :

1. Tekanan udara minimal dalam perancangan sistem pneumatik ini adalah 3,2482 bar. Bila tekanan pada kompresor adalah 5,9 bar, oleh karena tekanan yang dibutuhkan pada sistem pneumatik lebih kecil dari tekanan udara yang dihasilkan oleh kompresor, maka perancangan sistem pneumatik aman dan dapat diakomodasi oleh kapasitas kompresor yang tersedia pada kendaraan.

2. Dengan menggunakan alat ini waktu pengoperasian alat lebih cepat dan efektif, serta lebih mudah untuk digunakan dibandingkan dengan alat manual atau konvensional.

3. Meningkatkan aspek keamanan dan keselamatan dengan menggunakan flame trap berbasis pneumatik dibandingkan dengan alat manual atau konvensiona Spesifikasi Teknis Alat : 

https://doi.org/ 10.35894/jtk.v5i2.2

\begin{tabular}{|c|l|l|}
\hline No & \multicolumn{1}{|c|}{ PARAMETER } & \multicolumn{1}{c|}{ NILAI } \\
\hline 1 & $\begin{array}{l}\text { Tekanan yang } \\
\text { Dibutuhkan Untuk } \\
\text { Menggerakan Alat }\end{array}$ & $\begin{array}{l}>3,582 \\
\mathrm{kgf} / \mathrm{cm}^{2}\end{array}$ \\
\hline 2 & $\begin{array}{l}\text { Diameter Pipa Flame } \\
\text { Trap Stainless Steel } \\
\text { (Dflame) }\end{array}$ & $4 \mathrm{inch}$ \\
\hline 3 & Diameter Silinder & $63 \mathrm{~mm}$ \\
\hline 4 & Diameter Rod & $20 \mathrm{~mm}$ \\
\hline 5 & $\begin{array}{l}\text { Konduktivitas thermal } \\
\text { Acourete Fiber (kaf) }\end{array}$ & $10,996 \mathrm{~W} / \mathrm{m} . \mathrm{K}$ \\
\hline 6 & $\begin{array}{l}\text { Tebal Fiber } \\
1 \mathrm{~mm}=0,001 \\
\mathrm{~m}\end{array}$ \\
\hline 8 & $\begin{array}{l}\text { Diameter Tube } \\
\text { Polyethylene (D tube) }\end{array}$ & $\begin{array}{l}0,0064 \mathrm{~m} \text { atau } \\
1 / 4\end{array}$ \\
\hline & $\begin{array}{l}\text { Total Panjang Tube } \\
\text { Polyethylene (Dtube) }\end{array}$ & $2 \times 4,5 \mathrm{~m}=9 \mathrm{~m}$ \\
\hline
\end{tabular}

\section{DAFTAR PUSTAKA}

[1] Erlangga Fajar Satrio, Analisa Kerja Alat Penjebak Api pada Genset PLTG unit Gresik, Teknik Mesin Universitas Sepuluh November, 2016.

[2] Rizki Dwi Ramadhan, Evaluasi Prosedur Penanganan Keadaan Darurat Area Class 1 di TBBM Balongan, Universitas Gajah Mada, 2016.

[3] PT. PERTAMINA (Persero). "Modul Bahan Ajar BPA M\&T Batch 22013 Penerimaan \& Penyaluran BBM / BBK dengan Mobil Tangki ( Bridger )." 2013

[4] Parker Fluid Connectors. "Thermoplastic Tubing". (Catalog 4660). Ravenna, Ohio: Parflex Division, 2008

[5] PT. PERTAMINA (Persero). "Panduan Angkutan mobil tangki Volume 1 edisi 1."2007

[6] Buchori, Luqman. Perpindahan Panas. Semarang: Universitas Diponegoro, 2004.

[7] D. Merkle, B. Schrader \& M. Thomes. Hydraulics Basic Level Textbook. FESTO. Edition 11/200 
Jurnal Teknologi Kedirgantaraan, Vol, V No. 2, Agustus 2020, P-ISSN 2528-2778, E-ISSN 2684-9704 https://doi.org/ 10.35894/jtk.v5i2.2 